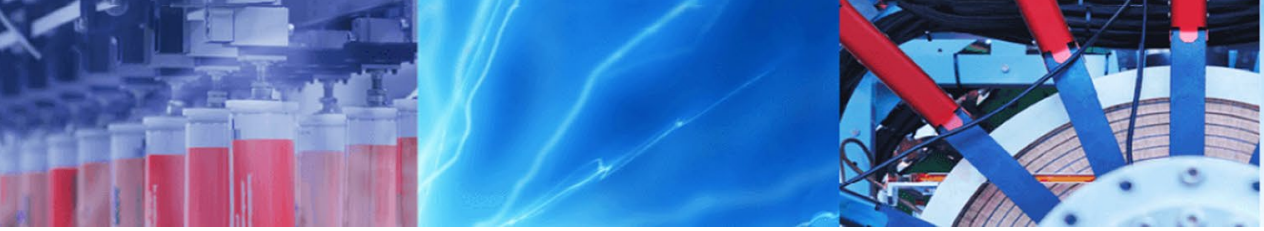

Research Article

\title{
In situ generation of silver and silver oxide nanoparticles on cotton fabrics using Tinospora cordifolia as bio reductant
}

\author{
Venkata Ramanamurthy Gollapudi ${ }^{1}$ Umamahesh Mallavarapu² (D) Jaswanth Seetha ${ }^{2,3}$. Prasad Akepogu ${ }^{2,3}$. \\ Venkateswara Rao Amara ${ }^{3} \cdot$ Hariram Natarajan ${ }^{4} \cdot$ Varadarajulu Anumakonda $^{5}$
}

Received: 7 December 2019 / Accepted: 25 February 2020 / Published online: 28 February 2020

(c) Springer Nature Switzerland AG 2020

\begin{abstract}
A simple, low cost and environmentally bioreduction method was adopted to in situ generate silver nanoparticles (AgNPs) on the surface of cellulose cotton fabrics utilizing Tinospora cordifolia leaf extract as reducing agent. The bio generation of AgNPs in nanocomposite cellulose cotton fabrics (NCCFs) was confirmed by Fourier Transform Infrared spectroscopy, Scanning Electron Microscopy along with Energy Dispersive X-ray (EDX) spectroscopy, X-ray Diffraction (XRD), primary and derivative thermogravimetric (TG and DTG) analysis and Differential Scanning Calorimetry (DSC). The generated AgNPs in NCCFs were found to be spherical in shape with an average size of $90 \mathrm{~nm}$. The presence of silver element was revealed by EDX spectra with an energy absorption peak at $3 \mathrm{keV}$. The bio synthesized AgNPs were found to be crystalline in nature from XRD. The bio generated AgNPs in NCCFs were found to be stable up to $399^{\circ} \mathrm{C}$ as confirmed by DTG and DSC analysis. These NCCFs also exhibited good mechanical properties. Further, these also exhibited good antibacterial activity against pathogenic disease producing Gram positive $\left(\mathrm{G}^{+v e}\right)$ and $\mathrm{Gram}$ negative $\left(\mathrm{G}^{-\mathrm{ve}}\right)$ bacteria. Basing on these properties, the prepared NCCFs can be considered for medical applications such as hospital bed materials, aprons etc. and also for packing applications.
\end{abstract}

Keywords In situ generation · TC leaf extract · Silver nanoparticles · Nanocomposite cellulose cotton fabrics . Mechanical properties $\cdot$ Anti-bacterial activity

\section{Introduction}

The diversified applications of nanomaterials play an important role in day to day activities of human beings [1, 2]. The nano sized materials are acting as bridge materials between macroscopic and microscopic materials with variety of functions [3]. Metal and metal oxide nanoparticles (MNPs \& MONPs) have attracted many researchers for diversified applications $[4,5]$. The synthesis of nanomaterials is generally carried out by various physical and chemical methods which are not eco-friendly [6]. However, the earlier physical, chemical and commercial methods have been proved to be competent for the synthesis of nanomaterials, but their repeated utilization may affect human health and the environment due to the usage of toxic chemicals, hazardous substances and production of poisonous byproducts and substances in some cases [7, 8]. An alternate method has to be searched by the scientists to overcome these problems. On comparison with earlier physical and chemical methods, green synthesis has found to be a faster, of low cost and environmentally benign method for the synthesis of nanomaterials [9-11].

\footnotetext{
$\triangle$ Umamahesh Mallavarapu, mahesh1962rgm@gmail.com | 'Department of Chemistry, V. R. College, Nellore, Andhra Pradesh, India. ${ }^{2}$ Department of Chemistry, Rajeev Gandhi Memorial College of Engineering and Technology, Nandyal, Andhra Pradesh, India. ${ }^{3}$ Department of Chemistry, Jawaharal Nehru Technological University, Ananatapur, Anantapuramu, Andhra Pradesh, India. ${ }^{4}$ Department of Biotechnology, Kalasalingam University, Krishnan Koil, Tamilnadu, India. ${ }^{5}$ Centre for Composite Materials, International Research Center, Kalasalingam University, Krishnan Koil, Tamilnadu, India.
} 
Vinayagam et al. synthesized zinc oxide nano flowers using Calliandra haematocephala plant species and carried their characterization and photocatalytic dye degradation [12]. Varadavenkateshan et al., utilized green synthesis method for the preparation of zinc oxide nanoparticles utilizing Cyanometra ramiflora leaf extract and studied the photocatalytic degradation of Rhodamine B [13]. Sanjanaanchan et al. prepared ferric oxide nanoparticles using biogenic synthesis method employing Peltophorum pterocarpum leaf extract and studied their catalytic degradation potential. [14]. Varadavenkateshan et al. synthesized silver nanoparticles using aqueous flower extract of Ipomoea digtata Linn and reported antibacterial activity [15]. In spite of several methods for the synthesis of MNPs, the researchers are utilizing in situ generation method due to minimization of agglomeration and inferior properties $[16,17]$. The researchers are now employing in situ method for the generation of MNPs and MONPs in polymer matrices to overcome agglomeration of nanoparticles which leads to low quality properties to the resulting nanocomposites [18]. In current times, in situ generation method was employed for the generation of nanocomposites with silver and copper nanoparticles $[19,20]$. Recently, the scientists are utilizing biogenic plant species parts as bio reductants and stabilizing agents for the synthesis of nanocomposites for the production of MNPs and MONPs using in situ generation method [21-23]. Tinospora cordifolia (TC) is one of the most divine plants of ayurvedic medicine and commonly known as Guduchi and Tippateega in southern parts of India [24]. The TC plant species parts are extensively employed for curing number of diseases and disorders of human beings. The TC plant acts as an adaptogen potent to release anxiety of stress, illness and increases resistance of human body. The leaf broth of TC mixed with Ocimum sanctum (Tulasi) is utilized as a medicine for curing dengue patients to increases the immunity and platelet count. The parts of TC plant are also employed to cure alleviate allergies, high fever gout arthritis, rheumatic disorders of inflammation, chronic skin disorders i.e. psoriasis-eczema were cured, reduce the side effects of chemotherapy drugs and for control of blood glucose levels. TC species is also used as a health supplement due to its anti-oxidant properties and capability to support the liver and immune system. Further, Guduchi also acts as an antiangiogenic [25-29]. Considering the significance of TC plant species parts in various medical applications, the authors in the present work employed aqueous TC leaf broth as reducing agent and its protein components as capping agents to generate AgNPs in NCCFs. FTIR, SEM, EDX, XRD, TG-DTG \& DSC, Tensile and antibacterial studies were carried out to confirm the generation of AgNPs on NCCFs by in situ generation method. The main aim of the authors was to use the NCCFs as antibacterial napkins, bandage cloth for wound cleaning and dressing, bed materials in hospitals and as disinfectant for killing disease producing bacteria in medical field and for packing applications.

\section{Experimental}

\subsection{Materials}

$\mathrm{AgNO}_{3}(\mathrm{AR})$, nutrient Agar (AR) sigma Aldrich make, white cotton cloth, $\mathrm{G}^{+\mathrm{ve}}$ and $\mathrm{G}^{-\mathrm{ve}}$ bacteria and TC leaves were utilized in the present research work.

\subsection{TC leaf broth preparation}

TC leaves were picked from the plant in early hours of morning which were washed with distilled water until all the dust, dirt and non-adhered impurities present on the leaves were removed and then dried. These leaves were cut into small pieces. $90 \mathrm{~g}$ of dried leaves were taken in a steel vessel containing $900 \mathrm{~mL}$ distilled water. The vessel was then placed on a thermally controlled hot plate at $80^{\circ} \mathrm{C}$ for $20 \mathrm{~min}$ with a constant stirring at $300 \mathrm{rpm}$ Peltophorum pterocarpum for obtaining TC leaf extract as reported in the literature [30]. The obtained leaf extract with light greenish color was filtered to get clear solution. The prepared leaf extract was kept in reagent bottles and stored at $5{ }^{\circ} \mathrm{C}$ in coolers till used to avoid fungus formation.

\subsection{Preparation of the matrix}

The white cellulose cotton fabric was rinsed and cleaned with deionized water and dried. It was then cut into $10 \mathrm{~cm} \mathrm{x}$ $28 \mathrm{~cm}$ pieces. $200 \mathrm{~mL}$ of prepared leaf extract solution was taken in $250 \mathrm{~mL}$ glass beaker. Two pieces of dried white cloth were rinsed in $250 \mathrm{~mL}$ beaker and kept on thermally controlled hot plate magnetic stirrer at $25^{\circ} \mathrm{C}$ for $24 \mathrm{~h}$ with a constant stirring at $250 \mathrm{rpm}$ with a magnetic bead. The white cotton cellulose fabric turned to light greenish color due to diffusion of leaf broth into it. It was removed and washed several times with deionized water until all nonadhered organic impurities of leaf extract were removed, dried and utilized as matrix.

\subsection{Generation of AgNPs on the surface of NCCFs by in situ method}

$250 \mathrm{~mL}$ of different concentrations (1-5 mM) of aqueous $\mathrm{AgNO}_{3}$ source solutions were prepared as per standard procedures and taken in separate beakers which were covered with a tin foil to avoid photo oxidation of silver. The prepared matrices were dipped in each source solution. These beakers were placed on magnetic stirrer at 
laboratory temperature with constant stirring ( $250 \mathrm{rpm})$ for 1 day. The light greenish color matrices turned to light brown due to instantaneous generation of AgNPs in NCCFs. The color of NCCFs intensified with increase in concentration of source solutions. These NCCFs were taken out, washed number of times with distilled water to remove unreacted $\mathrm{AgNO}_{3}$ and non-adherent impurities present on them, utilized for further studies. These were then air dried and stored.

\subsection{Characterization}

The NCCFs with in situ generated AgNPs were analyzed by FTIR spectrophotometer (BRUKER ALPHA-2, Billerica, MA. USA in the wavenumber range of $4000 \mathrm{~cm}^{-1}$ to $400 \mathrm{~cm}^{-1}$ with 32 scans at a resolution of $4 \mathrm{~cm}^{-1}$ ). The SEM images of NCCFs along with EDX were recorded using a scanning electron microscope (JEOL JSM IT-500 (Akishima, Tokyo, Japan) operated at $10 \mathrm{kV}$. The sizes of the AgNPs were measured using the inbuilt Smart Tiff software program of the microscope. TG-DTG and DSC thermograms were recorded employing Perkin Elmer Model STA6000analyzer (Westborough, MA, United States) at a heating rate of $10{ }^{\circ} \mathrm{C} / \mathrm{min}$ in Nitrogen atmosphere. The XRD spectra were recorded using RIGAKU MINI FLEX-600 X-ray diffractometer operated at $40 \mathrm{kV}$ and $30 \mathrm{~mA}$ in the $2 \theta=10^{\circ}$ to $80^{\circ}$ range at a scanning rate of $4 \% \mathrm{~min}$ to further confirm the bio generation of AgNPs on the surface of NCCFs. The NCCFs were also tested for their pathogenic antibacterial activity using disc method as reported in the literature [31]. The bacterial cultures of S. aureus (AATCC 6538) and $P$. aeruginosa (AATCC 27853) were tested by a standard test (AATCC 100). The mechanical properties were determined using Instron-3369 Universal testing machine (Norwood, MA 02062-2643, USA). The specifications as per ASTM D 638 were followed. The rectangular specimens with dimensions of $150 \mathrm{~mm}$ length and $10 \mathrm{~mm}$ width were employed with a gauge length of $50 \mathrm{~mm}$. The experiments were conducted at an extension rate of $5 \mathrm{~mm} / \mathrm{min}$. In each case, 5 specimens were tested and their average values are reported.

\section{Results and discussion}

\subsection{Preliminary confirmation by persistent color of NCCFs}

The in situ generation of AgNPs on the surface of NCCFs was preliminarily examined by color change of the fabric during and at the end of the synthesis. The appearance of the NCCFs using 1-5 mM source solutions, matrix and white cloth were photographed and the digital images are presented in Fig. 1. The color of the white cloth (Fig. 1a) changed to light green due to the diffusion of leaf broth and formed the matrix (Fig. 1b). The colors of the NCCFs changed to light brown (Fig. 1c-g). It can be seen from Fig. 1c-g that the color of NCCFs intensified with increase in the concentration of source solutions and did not diminish even after number of washings with distilled water. The physical visual change of color between the matrix and NCCFs preliminarily confirms the generation of silver based nanoparticles.

\subsection{SEM with EDX analysis}

The surface characteristics of generated AgNPs in NCCFs, particle size distribution and the presence of elemental silver were confirmed by SEM along with EDX analysis. The digital SEM images of generated AgNPs on the surface of NCCFs (1-5 mM) were recorded. For more precision, the SEM and EDX images of NCCFs with $1 \mathrm{mM} \mathrm{AgNO}_{3}$ solution is presented in Fig. 2a, b, respectively. Smart tiff program was used to measure the particle size of AgNPs on NCCFs at different areas. The size distribution of AgNPs in NCCFs is shown in Fig. 2C, as histograms. An absorption energy band at $3 \mathrm{keV}$ from EDX spectra reveals the presence of metallic silver (Fig. 2b). A similar observation was made by earlier workers [32]. It can be observed from the histograms (Fig. 2c) that in the case of NCCF using minimum concentration of $\mathrm{AgNO}_{3}$ the size of the generated AgNPs was in the size range of $41-140 \mathrm{~nm}$. On the other hand, when the higher concentrated source solution was used, the resulting NCCFs had the generated AgNPs in the size range of $41-160 \mathrm{~nm}$ (not shown in the Figure).
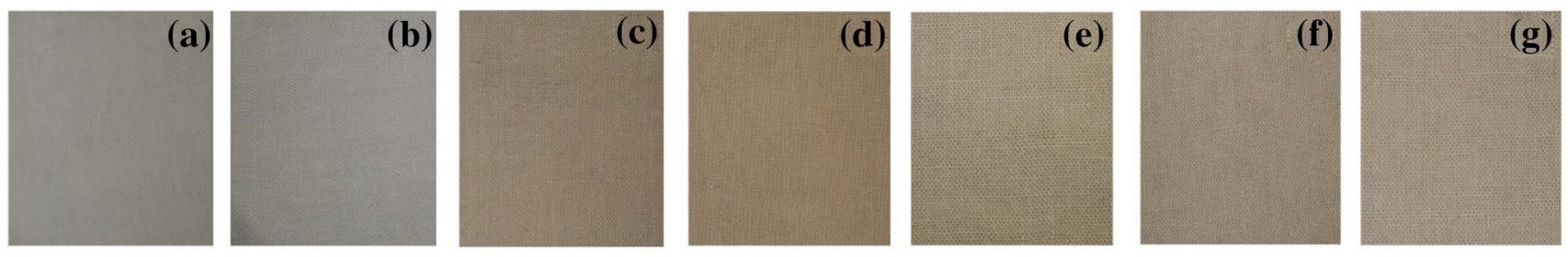

Fig. 1 Digital photographs of a white cloth; b matrix; c-g AgNPs in NCCFs (1-5 mM) 

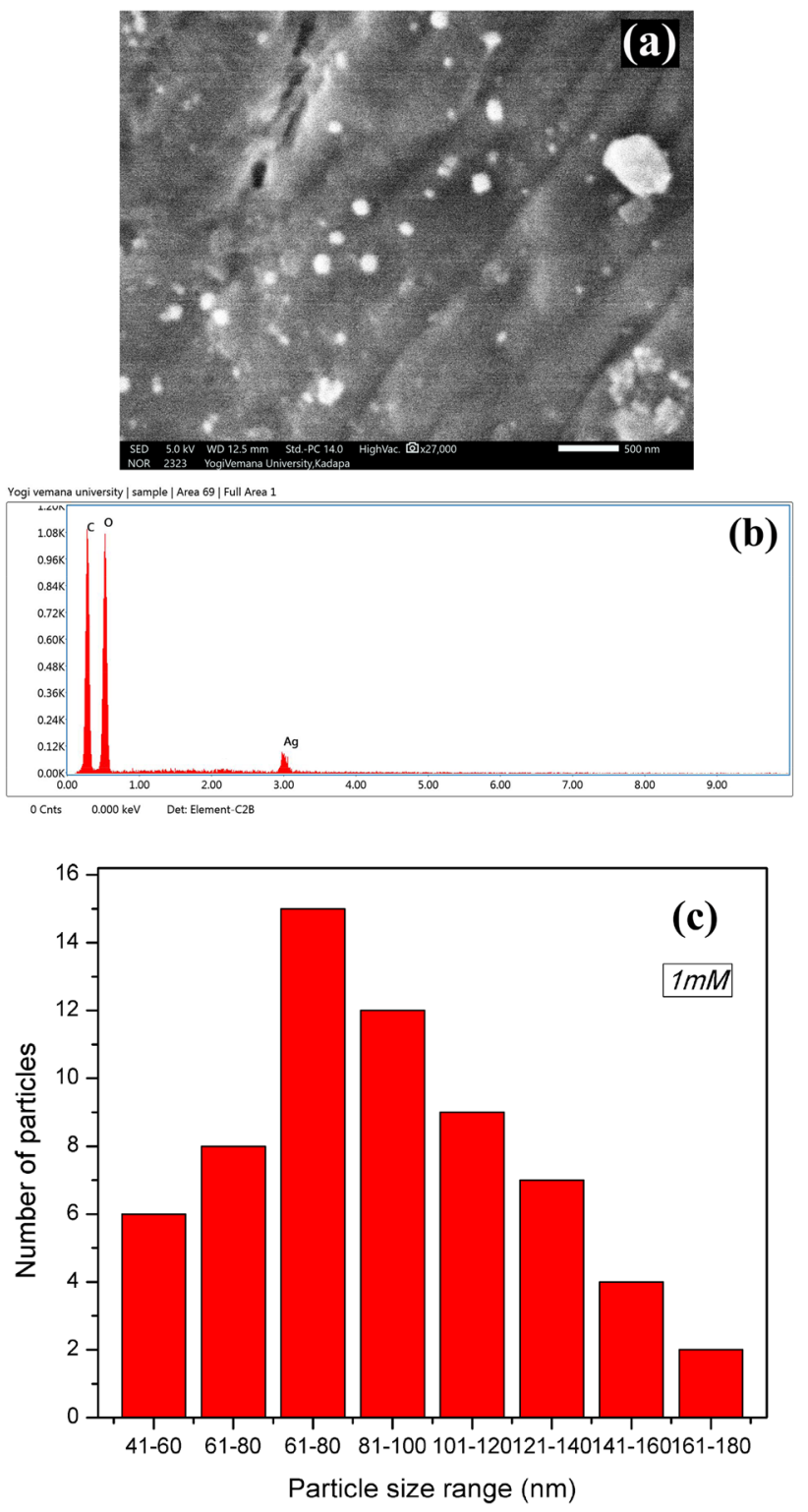

Fig. 2 SEM microgram (a), EDX (b) and $\mathbf{c}$ Histograms of NCCF made using $1 \mathrm{mM} \mathrm{AgNO}_{3}$ source solution

Bio generated AgNPs in NCCFs in all the cases were found to be globular in shape with an average size of $90 \mathrm{~nm}$. Thus the SEM with EDX analysis confirms the formation of AgNPs on NCCFs.

\subsection{FTIR spectral analysis}

To probe the chemical interactions between the cellulose cotton fabric and matrix and the generated AgNPs in NCCFs, FTIR spectral analysis was carried. The recorded FTIR spectra of cellulose cotton fabric and matrix are presented in Fig. 3a while those of the matrix and NCCFs in Fig. 3b. FTIR spectra of matrix and cellulose cotton fabrics, as shown in Fig. 3a are overlapping with each other which indicate the presence of similar functional molecularities in them. Further, it can be noticed that the matrix exhibited slightly higher intensity of absorption than white cloth due to diffusion of molecularities from TC leaf extract into cotton fabrics. From Fig. 3b, the absorption band at $3251 \mathrm{~cm}^{-1}$, corresponds to $-\mathrm{OH}$ functional groups present in alkaloids, flavonoids, glycosides, steroids and poly alcohols present in TC leaf extract [33]. The other absorption bands at $2860 \mathrm{~cm}^{-1}, 1630 \mathrm{~cm}^{-1}, 1312 \mathrm{~cm}^{-1}$ and $1004 \mathrm{~cm}^{-1}$ were due to $\mathrm{C}-\mathrm{H}$ stretching vibrations of alkanes, $\mathrm{C}=\mathrm{O}$ stretching vibration of fatty acids, carboxylic $\mathrm{O}-\mathrm{H}$ bending vibration of fatty acids and $\mathrm{C}-\mathrm{O}$ and $\mathrm{C}-\mathrm{O}-\mathrm{C}$ stretching vibrations, respectively [34]. Further, it is also noticed that the intensity of absorption peak exhibited by NCCFs, using different $\mathrm{AgNO}_{3}$ source solutions (1-5 mM) was lower than that of matrix at $3251 \mathrm{~cm}^{-1}$, indicating the involvement of $-\mathrm{OH}$ functional group of TC leaf extract in the bio reduction of $\mathrm{Ag}^{+}$ions in to $\mathrm{Ag}^{0}$. The other peaks of NCCFs except at $1004 \mathrm{~cm}^{-1}$ have not shown any difference in their intensity as compared to matrix. In the case of NCCFs ( $1 \mathrm{mM}$ and $2 \mathrm{mM}$ ), the observed peak at $1004 \mathrm{~cm}^{-1}$ exhibited higher intensity than matrix, owing to use of lower concentrations of $\mathrm{AgNO}_{3}$ source solutions which are less effective on molecular functionalities of the matrix. At higher concentrations (3-5 mM), the NCCFs exhibited higher intensity than matrix due to generation of more number of AgNPs and more effect on matrix (Fig. 4).

A possible mechanism was proposed for the bio reduction of $\mathrm{Ag}^{+}$ions into AgNPs which are instantaneously generated on NCCFs, utilizing molecular functionalities present in aqueous leaf extract. The chemical constituents present in TC leaves such as flavonoids, alkaloids, poly phenols are responsible for the reduction of $\mathrm{Ag}+$ ions into AgNPs. A similar observation was also made by earlier researchers [33, 35]. Syringin, a constituent in Glycosides, present in leaf extract of TC contains two hydroxyl functional groups. These two hydroxyl functional groups were involved in bio reduction of $2 \mathrm{Ag}^{+}$ions into two silver metal atoms leading to the formation of AgNPs. The involvement of hydroxyl functional groups for reduction of two $\mathrm{Ag}^{+}$in to two $\mathrm{Ag}^{0}$ was reported in literature by earlier workers also [36].

\subsection{XRD analysis}

To verify the crystallinity of generated AgNPs in NCCFs, XRD studies were carried. The recorded diffractograms of NCCFs and matrix for comparison are shown in Fig. 5a. The matrix and NCCFs exhibited similar energy peaks (Fig. 5a). However, the diffractograms of NCCFs showed more intensity than matrix due to the formation of AgNPs. Matrix and AgNPs in NCCFs both resulted peaks at $2 \theta=15.1^{\circ}$, 

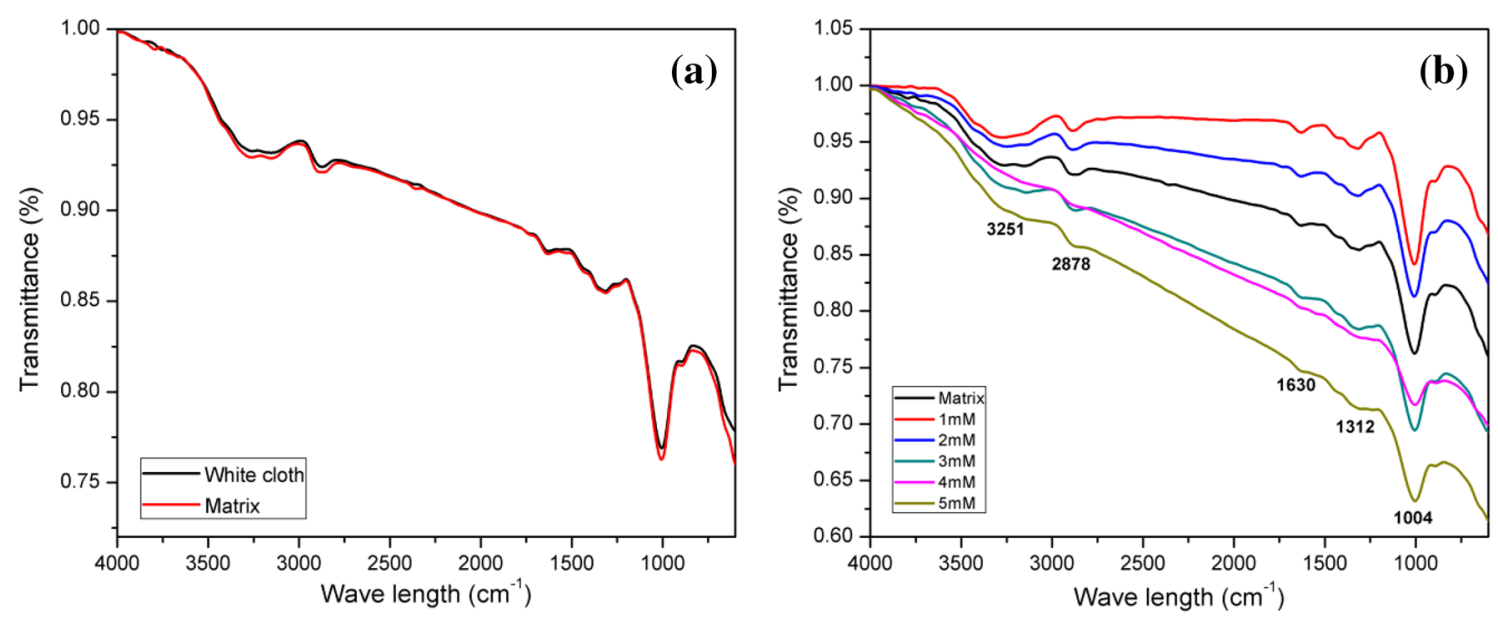

Fig. 3 FTIR spectra of a matrix and white cotton fabric; $\mathbf{b}$ AgNPs in NCCFs and matrix

Fig. 4 Mechanism of formation of AgNPs using functional groups present in glycoside of TC leaf extract

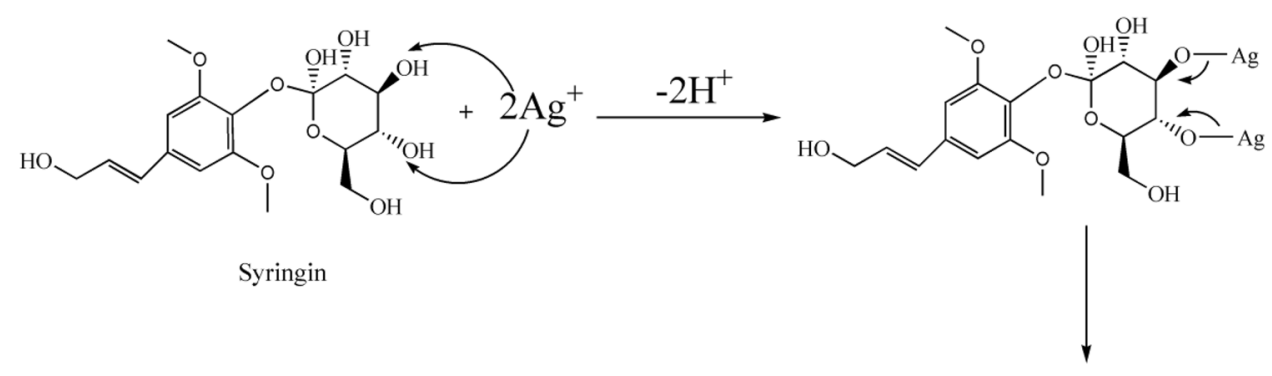<smiles>COc1cc(/C=C/CO)cc(OC)c1OC1(O)O[C@H](CO)C(=O)C(=O)[C@H]1O</smiles>
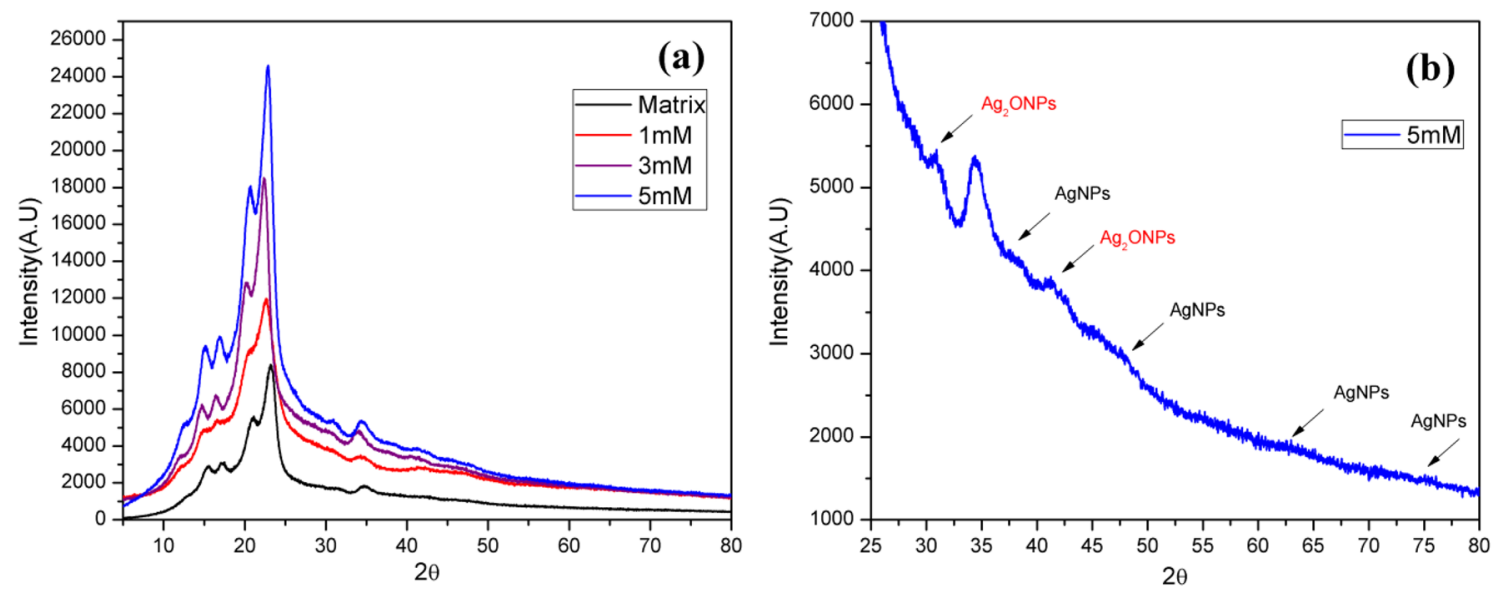

Fig. 5 XRD studies of NCCFs (1, 3 and $5 \mathrm{mM})$ and matrix (a); and expanded XRD of NCCF (5 mM) (b)

$17.2^{\circ}, 22.7^{\circ}$ and $34.6^{\circ}$, corresponding to reflections from (1-10), (101), (002) and (040) planes respectively indicating their cellulose-I structure [37]. To observe the peaks corresponding to the generated silver based nanoparticles, the diffractogram of NCCF ( $5 \mathrm{mM}$ ) was expanded in $2 \theta=25^{\circ}$ to $80^{\circ}$ range, as shown in Fig. $5 \mathrm{~b}$. The observed 
peaks at $2 \theta=30.6^{\circ}$ and $41.2^{\circ}$ with the corresponding miller indices (111) and (200) are related to $\mathrm{Ag}_{2} \mathrm{O}$ nanoparticles. The other energy peaks at $2 \theta=38.7^{\circ}(111), 46.3^{\circ}(200)$, $63.2^{\circ}(220)$ and $75.8^{\circ}(311)$ belong to AgNPs. Amara et al. [38] and Jayaseelan et al. [39] noticed similar type of peaks in the synthesis of silver based nanoparticles on NCCFs. The XRD studies revealed that both $\mathrm{Ag}_{2} \mathrm{O}$ nanoparticles and AgNPs were generated on NCCFs which were crystalline in nature with face centered cubic (FCC) lattice structure. The results from XRD studies were in accordance with SEM analysis.

\subsection{TG-DTG and DSC analysis}

Bio synthesized NCCFs with in situ generated silver based nanoparticles were tested for their thermal stability using TG and DTG analysis. As an example, the primary thermograms of NCCFs using $1 \mathrm{mM}, 3 \mathrm{mM}$ and $5 \mathrm{mM}$ source solutions and the matrix are presented in Fig. $6 \mathrm{a}$. The corresponding derivative thermograms are depicted in Fig. 6b. From Fig. 6a, b, it is evident that both the NCCFs and matrix showed thermal degradation in two stages. The initial phase of thermal deterioration was noticed between 42 and $184^{\circ} \mathrm{C}$. This stage of degradation may be due to evaporation of volatile compounds and moisture present in NCCFs and matrix. The second phase of thermal degradation was noticed in the temperature range of 272 to $399^{\circ} \mathrm{C}$ and 296 to $423^{\circ} \mathrm{C}$ for NCCFs and matrix, respectively. From Fig. 6a, b, it is perceived that the generated AgNPs in NCCFs slightly lowered their thermal stability than the matrix, owing to catalytic activity of AgNPs. A similar observation was also made by earlier researchers [40]. However, NCCFs were still stable up to $399^{\circ} \mathrm{C}$, which is far above the usage and washing temperatures. For further confirmation, DSC studies were also conducted and the obtained DSC thermograms are presented in Fig. $6 \mathrm{c}$. The DSC thermograms also revealed that the degradation of NCCFs was lower than that of matrix.

\subsection{Mechanical properties}

Polymer nanocomposites have drawn more attention by various researchers due to their light weight, low cost and high strength to weight ratio $[41,42]$. In order to study the effect of the generated silver based nanoparticles on the mechanical properties of the NCCFs, the tensile parameters such as maximum tensile stress, Young's modulus and \% elongation at break were determined using UTM. The stress-strain curves of the white cloth, matrix and the NCCFs using $1 \mathrm{mM}$ (minimum) and $5 \mathrm{mM}$ (maximum) source solutions are presented in Fig. 7. The corresponding computed maximum tensile stress, Young Modulus, \% Elongation at break and the maximum load are presented in Table 1. From Table 1, it can be observed that the NCCFs possessed higher tensile stress, modulus and maximum load while the \% elongation was lower when compared to those of both the white cloth and the

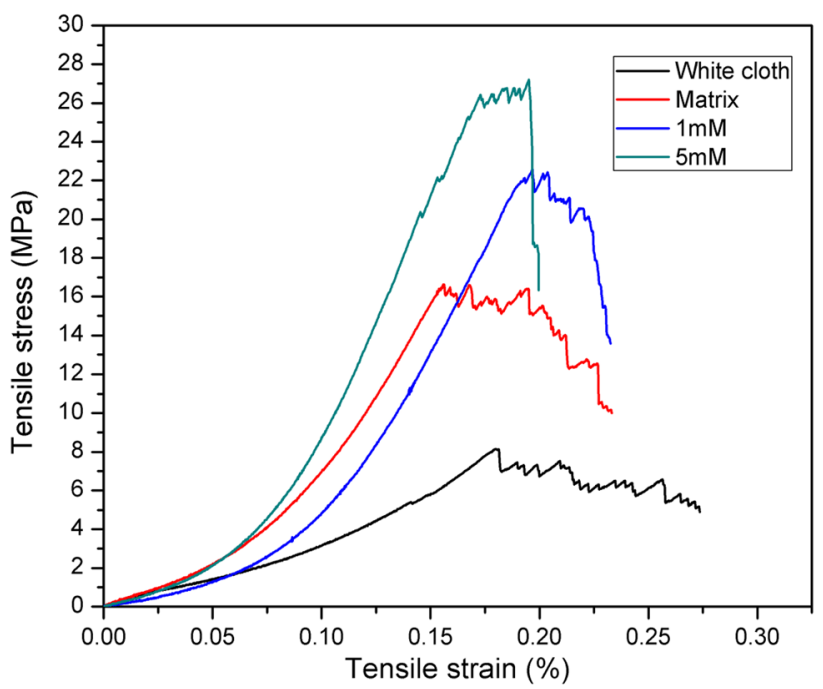

Fig. 7 Tensile stress-strain curves of NCCFs, white cotton cloth and matrix
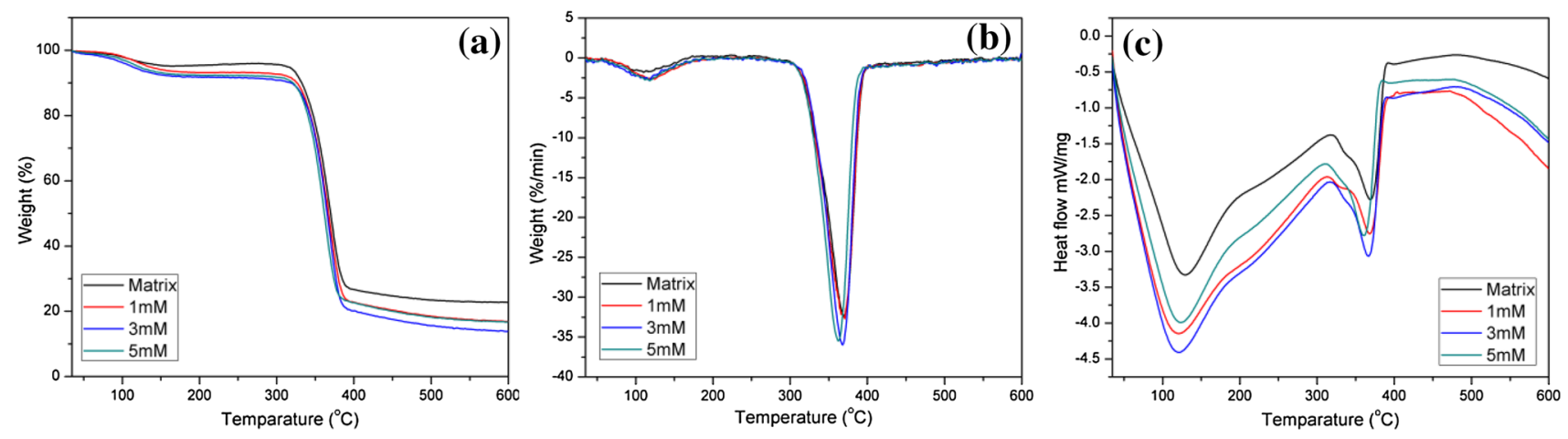

Fig. 6 TG (a); DTG (b) and DSC (c) of NCCFs and matrix 
Table 1 Tensile parameters of white cloth, matrix and NCCFs with generated AgNPs using $1 \mathrm{mM}$ and $5 \mathrm{mM}$ source solutions

\begin{tabular}{llcll}
\hline Type of cloth & $\begin{array}{l}\text { Tensile } \\
\text { strain } \\
(\%)\end{array}$ & $\begin{array}{l}\text { Tensile } \\
\text { stress } \\
(\mathrm{MPa})\end{array}$ & $\begin{array}{l}\text { Young's } \\
\text { modulus } \\
(\mathrm{MPa})\end{array}$ & $\begin{array}{l}\text { Maximum load } \\
(\mathrm{N})\end{array}$ \\
\hline White cloth & 0.27 & 8.52 & 190.85 & 59.07 \\
Matrix & 0.23 & 16.65 & 189.11 & 91.56 \\
$1 \mathrm{mM}$ & 0.22 & 22.59 & 214.35 & 129.84 \\
$5 \mathrm{mM}$ & 0.19 & 27.22 & 269.90 & 176.92 \\
\hline
\end{tabular}

matrix. For NCCF prepared using $1 \mathrm{mM}$ source solution, the maximum tensile stress and \%elongation at break were found to be $22.6 \mathrm{MPa}$ and 0.22 respectively at a maximum load of $128.9 \mathrm{~N}$. These values for white cloth (maximum stress of $8.5 \mathrm{MPa}$ and \%elongation at break of 0.27 for a maximum load of $59 \mathrm{~N}$ ) and matrix (maximum stress of 16.7 MPa and \%elongation at break of 0.23 for a maximum load of $91.6 \mathrm{~N}$ ) were found to be lower than those of the NCCFs. In the case of the NCCF made using $5 \mathrm{mM}$ source solution, the maximum stress and the \% elongation at break were found to be $27.2 \mathrm{MPa}$ and 0.19 respectively at a maximum load of $176.9 \mathrm{~N}$. Further, the Young's modulus for the NCCF using $5 \mathrm{mM}$ source solution was found to be 269.9 MPa. These observations indicate that the generated silver based nanoparticles enhanced the tensile stress and modulus of the NCCFs.

\subsection{Antibacterial activity of NCCFs}

It is already established and well known that silver metal annihilates the disease causing pathogenic bacteria [43,
44]. In order to examine whether the prepared NCCFs also exhibit antibacterial activity or not, the antibacterial test by disc method was carried out against Staphylococcus aureus (S. aureus) $\left(\mathrm{G}^{+\mathrm{ve}}\right.$ ) and Pseudomonas aeruginosa (P. aeruginosa) pathogenic $\left(\mathrm{G}^{-\mathrm{ve}}\right)$ bacteria. The zones of inhibition for NCCFs against both $\mathrm{G}^{\text {+ve }}$ and $\mathrm{G}^{\text {-ve }}$ bacteria were photographed and are presented in Fig. $8 \mathrm{a}$, b respectively. For comparison, the test was also carried for white cellulose fabric and the matrix. The diameters of inhibition zones were measured and the values are presented in Table 2. From Table 2 and from Fig. 8, it can be deduced that the generated AgNPs on NCCFs exhibited good antibacterial activity and are comparable with that reported in some other cases by earlier researchers [31, 38]. Hence, the antibacterial NCCFs can be considered for making bandage cloth for wound cleaning and dressing and also for surgical aprons and bed materials for hospitals, napkins etc. A possible general mechanism of killing of pathogenic

Table 2 Killing Zone of inhibition exhibited by NCCFs, white cloth and matrix against both bacteria

\begin{tabular}{lcc}
\hline Sample type with label & \multicolumn{2}{c}{ Diameter of clear zone $(\mathrm{mm})$} \\
\cline { 2 - 3 } & P. aeruginosa & S. aureus \\
\hline White cloth (1) & 0 & 0 \\
Matrix (2) & 0 & 0 \\
$1 \mathrm{mM} \mathrm{(3)}$ & 15 & 14 \\
$2 \mathrm{mM} \mathrm{(4)}$ & 16 & 16 \\
$3 \mathrm{mM} \mathrm{(5)}$ & 16 & 18 \\
$4 \mathrm{mM} \mathrm{(6)}$ & 18 & 20 \\
$5 \mathrm{mM} \mathrm{(7)}$ & 18 & 21 \\
\hline
\end{tabular}

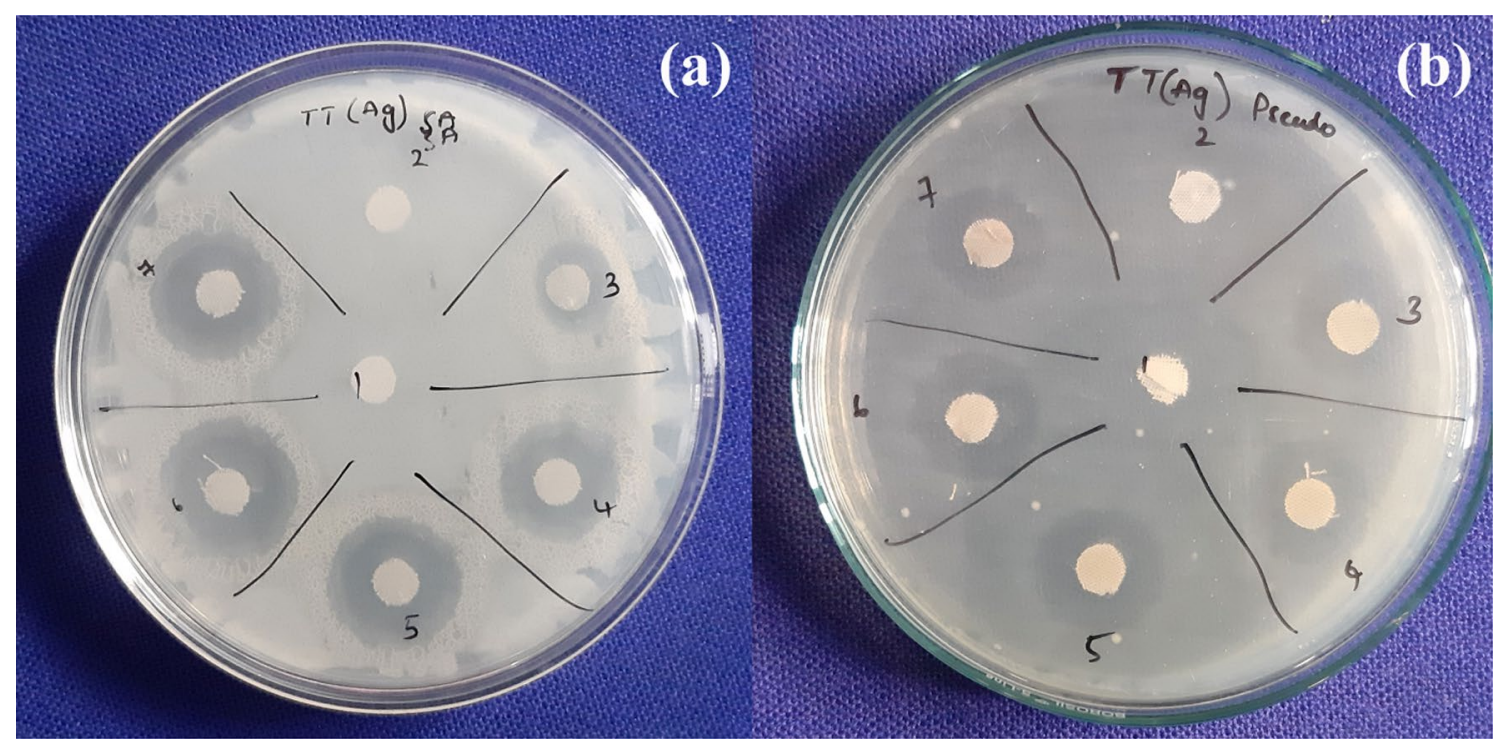

Fig. 8 Zones of inhibition of NCCFs along with matrix and white cotton fabric 
Fig. 9 Action mechanism of AgNPs on pathogenic bacteria

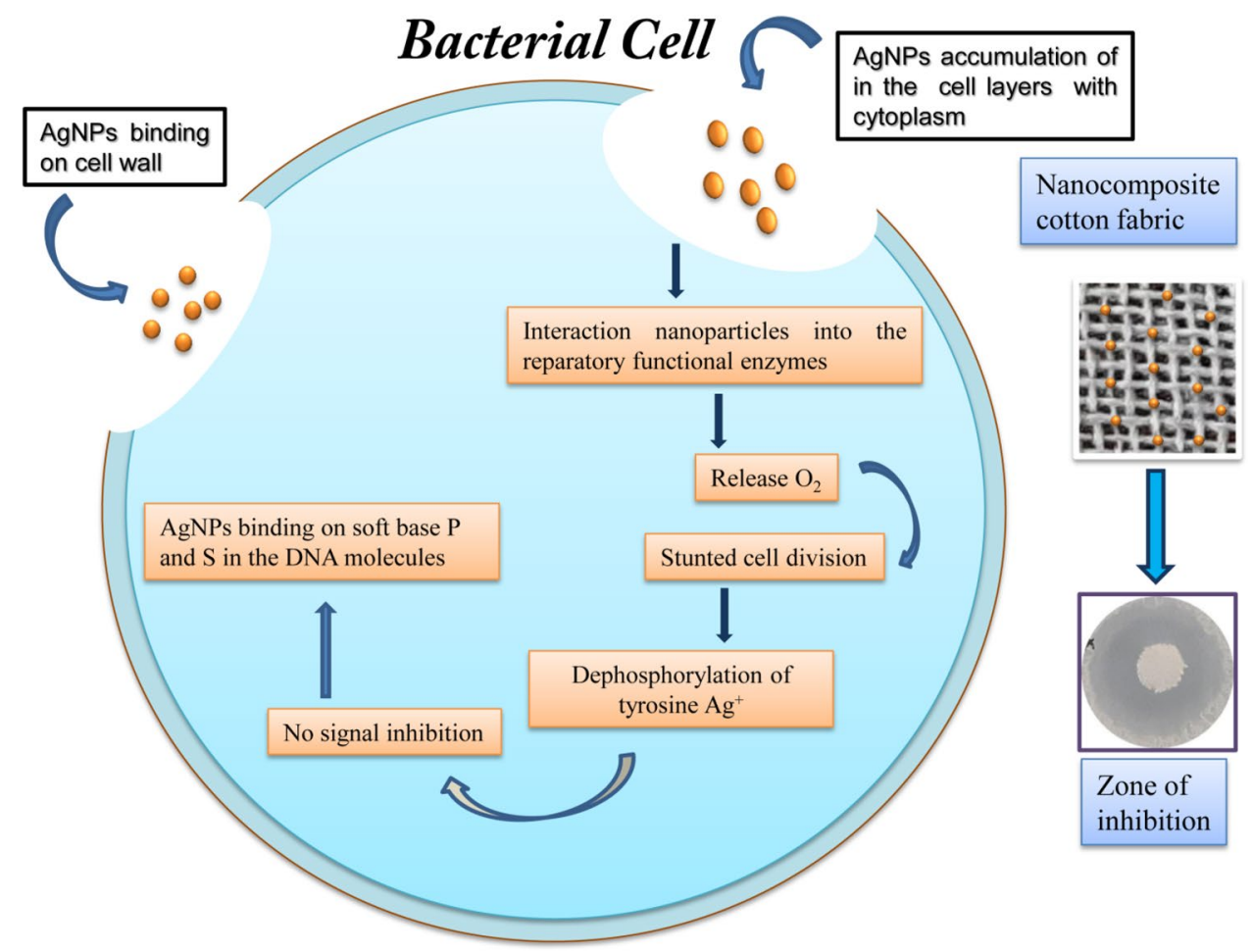

bacteria is presented in Fig. 9. From Fig. 9, it can be inferred that the AgNPs can be adhered to cell wall of bacteria. The respiratory enzymes in bacterial cells are in contact with silver based nanoparticles and inhibit several functions in the cell and damage the cells [45]. As a result, there will be generation of reactive oxygen species, which are produced possibly through the inhibition of a respiratory enzyme by silver ions and attack the cell itself. AgNPs may bind on soft base $P$ and $S$ in the DNA molecule of bacteria.

\section{Conclusions}

A simple, low cost and environmentally benign bio reduction technique was involved in the present work for the generation of AgNPs in NCCFs, using aqueous TC plant leaf extract as a reducing agent. The generation of AgNPs on NCCFs was confirmed by SEM analysis and the nanoparticles were found to be globular in shape with a mean size of $90 \mathrm{~nm}$. EDX analysis confirmed the presence of Ag metal by the presence of an energy peak at $3 \mathrm{keV}$. The generated AgNPs were with face centered cubic (FCC) lattice structure as confirmed by XRD analysis. TG-DTG analysis and DSC studies revealed slightly lower thermal stability for NCCFs when compared to both the white cloth and the matrix due to the catalytic activity of the generated AgNPs. Further, the prepared NCCFs had higher tensile and antibacterial properties than the matrix. Hence, these NCCFs can be utilized for making packing materials and in medicine as surgical aprons, bed materials, napkins etc.

Acknowledgements We sincerely express our thanks to Chemistry department and the authorities, RGMCET, Nandyal, for providing needful requirements.

\section{Compliance with ethical standards}

Conflict of interest We declare that we have no conflict of interest.

Human participants and animals The research work of this paper has not involved any human participants and animals.

\section{References}

1. Benelli G (2016) Plant-mediated biosynthesis of nanoparticles as an emerging tool against mosquitoes of medical and veterinary importance: a review. Paras Res 115:23-34. https://doi. org/10.1007/s00436-015-4800-9

2. Ahmed S, Saifullah AM, Swami BL, Ikram S (2016) Green synthesis of silver nanoparticles using Azadirachta indica aqueous leaf extract. J Radiat Res Appl Sci 9:1-7. https://doi.org/10.1016/j. jrras.2015.06.006

3. Birusanti $A B$, Mallavarapu U, Nayakanti D, Espenti CS, Mala $S$ (2018) Sustainable green synthesis of silver nanoparticles by using Rangoon creeper leaves extract and their spectral analysis and anti-bacterial studies. IET Nanobiotechnol 13:71-76. https ://doi.org/10.1049/iet-nbt.2018.5117

4. Iravani S (2011) Green synthesis of metal nanoparticles using plants. Green Chem 13:2638-2650. https://doi.org/10.1039/ C1GC15386B

\section{SN Applied Sciences}


5. Virkutyte J, Varma RS (2011) Green synthesis of metal nanoparticles: biodegradable polymers and enzymes in stabilization and surface functionalization. Chem Sci 2:837-846. https://doi. org/10.1039/COSC00338G

6. Choi YJ, Park HH (2011) Direct patterning of $\mathrm{SnO}_{2}$ composite films prepared with various contents of $\mathrm{Pt}$ nanoparticles by photochemical metal-organic deposition. Thin Solid Films 519:6214-6218. https://doi.org/10.1016/j.tsf.2011.03.051

7. Sánchez GR, Castilla CL, Gómez NB, García A, Marcos R, Carmona ER (2016) Leaf extract from the endemic plant Peumus boldus as an effective bioproduct for the green synthesis of silver nanoparticles. Mater Lett 183:255-260. https://doi.org/10.1016/j. matlet.2016.07.115

8. Anandalakshmi K, Venugobal J (2017) Green synthesis and characterization of silver nanoparticles using Vitex negundo (KaruNochchi) leaf extract and its antibacterial activity. Med Chem 7:218-225. https://doi.org/10.4172/2161-0444.1000460

9. Yadav $\mathrm{P}$, Manjunath $\mathrm{H}$, Selvaraj R (2018) Antibacterial and dye degradation potential of zero-valent silver nanoparticles synthesised using the leaf extract of Spondias dulcis. IET Nanobiotechnol 13(1):84-89. https://doi.org/10.1049/iet-nbt.2018.5058

10. Sirdeshpande KD, Sridhar A, Cholkar KM, Selvaraj R (2018) Structural characterization of mesoporous magnetite nanoparticles synthesized using the leaf extract of Calliandra haematocephala and their photocatalytic degradation of malachite green dye. Appl Nanosci 8(4):675-683. https://doi.org/10.1007/s1320 4-018-0698-8

11. Vinayagam R, Varadavenkatesan T, Selvaraj R (2018) Green synthesis, structural characterization, and catalytic activity of silver nanoparticles stabilized with Bridelia retusa leaf extract. Green Process Synth 7(1):30-37. https://doi.org/10.1515/ gps-2016-0236

12. Vinayagam $R$, Selvaraj $R$, Arivalagan $P$, Varadavenkatesan $T$ (2020) Synthesis, characterization and photocatalytic dye degradation capability of Calliandra haematocephala-mediated zinc oxide nanoflowers. J Photochem Photobiol B Biol 203:111760. https ://doi.org/10.1016/j.jphotobiol.2019.111760

13. Varadavenkatesan $T$, Lyubchik E, Pai S, Pugazhendhi A, Vinayagam R, Selvaraj R (2019) Photocatalytic degradation of Rhodamine $B$ by zinc oxide nanoparticles synthesized using the leaf extract of Cyanometra ramiflora. J Photochem Photobiol B Biol 199:111621. https://doi.org/10.1016/j.jphotobiol.2019.111621

14. Anchan S, Pai S, Sridevi H, Varadavenkatesan T, Vinayagam R, Selvaraj R (2019) Biogenic synthesis of ferric oxide nanoparticles using the leaf extract of Peltophorum pterocarpum and their catalytic dye degradation potential. Biocatal Agric Biotechnol 20:101251. https://doi.org/10.1016/j.bcab.2019.101251

15. Varadavenkatesan T, Selvaraj R, Vinayagam R (2019) Dye degradation and antibacterial activity of green synthesized silver nanoparticles using Ipomoea digitata Linn (2019) flower extract. Int J Environ Sci Technol 16(5):2395-2404. https://doi.org/10.1007/ s13762-018-1850-4

16. Venkateswara Rao A, Ashok B, Uma Mahesh M, VenkataSubbareddy G, Chandra Sekhar V, VenkataRamanamurthy G, VaradaRajulu A (2019) Antibacterial cotton fabrics with in situ generated silver and copper bimetallic nanoparticles using red sanders powder extract as reducing agent. Int J Polym Anal Charact 24:346-354. https://doi.org/10.1080/10236 66X.2019.1598631

17. Pusphalatha R, Ashok B, Hariram N, Rajulu AV (2019) Nanocomposite polyester fabrics with in situ generated silver nanoparticles using tamarind leaf extract reducing agent. Int J Polym Anal Charact 9:1-9. https://doi.org/10.1080/1023666X.2019.1614265

18. He J, Kunitake T, Nakao A (2003) Facile in situ synthesis of noble metal nanoparticles in porous cellulose fibers. Chem Mater 15:4401-4406. https://doi.org/10.1021/cm034720r
19. Amara VR, Basa A, Mallavarapu UM, Vatti C, Gopireddy SV, Anumakonda V (2019) Preparation and properties of cotton nanocomposite fabrics with in situ generated copper nanoparticles using Red sanders powder extract as a reducing agent. Inorg Nano Met Chem 49:343-348. https://doi.org/10.1080/24701 556.2019.1661437

20. Sadanand V, Tian H, Rajulu AV, Satyanarayana B (2017) Antibacterial cotton fabric with in situ generated silver nanoparticles by one-step hydrothermal method. Int J Polym Anal Charact 22:275-279. https://doi.org/10.1080/1023666X.2017.1287828

21. Mamatha G, VaradaRajulu A, Madhukar K (2018) In situ generation of bimetallic nanoparticles in cotton fabric using aloe vera leaf extract, as a reducing agent. J Nat Fibers 24:1-9. https://doi.org/10.1080/15440478.2018.1558146

22. Surendra TV, Roopan SM (2016) Photocatalytic and antibacterial properties of phytosynthesized $\mathrm{CeO}_{2} \mathrm{NPs}$ using Moringa oleifera peel extract. J Photochem Photobiol B Biol 161:122128. https://doi.org/10.1016/j.jphotobiol.2016.05.019

23. Roopan SM, Surendra TV, Elango G, Kumar SHS (2014) Biosynthetic trends and future aspects of bimetallic nanoparticles and its medicinal applications. Appl Microbiol Biotechnol 98:5289-5300. https://doi.org/10.1007/s00253-014-5736-1

24. Singh SS, Pandey SC, Srivastava S, Gupta VS, Patro B, Ghosh AC (2003) Chemistry and medicinal properties of Tinospora cordifolia (Guduchi). Ind J Pharm 35:83-91

25. Sinha K, Mishra NP, Singh J, Khanuja SPS (2004) Tinospora cordifolia (Guduchi), a reservoir plant for therapeutic applications: a review. Ind J Trad Know 3:257-270. http://hdl.handl e.net/123456789/9359

26. Shefali C, Nilofer S (2013) Gaduchi-the best ayurvedic herb. Pharm Innov 2:97

27. Choudhary N, Siddiqui MB, Azmat S, Khatoon S (2013) Tinospora cordifolia: ethnobotany, phytopharmacology and phytochemistry aspects. Int J Pharm Sci Res 4:891-897

28. Saha S, Ghosh S (2012) Tinospora cordifolia: one plant, many roles. Anc Sci Life 31:151-155. https://doi.org/10.4103/02577941.107344

29. Sharma V, Pandey D (2010) Beneficial effects of Tinospora cordifolia on blood profiles in male mice exposed to lead. Toxicol Int 17:8-11. https://doi.org/10.4103/0971-6580.68341

30. Kishanji M, Mamatha G, Obi Reddy K, VaradaRajulu A, Madhukar K (2017) In situ generation of silver nanoparticles in cellulose matrix using Azadirachta indica leaf extract as a reducing agent. Int J Polym Anal Charact 22:734-740. https://doi. org/10.1080/1023666X.2017.1369612

31. Sadanand V, Rajini N, Satyanarayana B, Rajulu AV (2016) Preparation and properties of cellulose/silver nanoparticle composites with in situ-generated silver nanoparticles using Ocimum sanctum leaf extract. Int J Polym Anal Charact 21:408-416. https://doi.org/10.1080/1023666X.2016.1161100

32. Muthulakshmi L, Rajini N, Nellaiah H, Kathiresan T, Jawaid M, Rajulu AV (2017) Experimental investigation of cellulose/ silver nanocomposites using in situ generation method. J Polym Environ 25:1021-1032. https://doi.org/10.1007/s1092 4-016-0871-7

33. Reddy NM, Reddy RN (2015) Tinospora cordifolia chemical constituents and medicinal properties: a review. Sch Acad J Pharm 4:364-369

34. Padma M, Govindh B, Rao BV (2014) Synthesis and characterization of fluorescent silver nanoparticles stabilized by Tinospora cordifolia leaf extract-a green procedure. Int J Eng Res Ind Appl 4:100-107

35. Bonvicini F, Mandrone M, Antognoni F, Poli F, Angela Gentilomi G (2014) Ethanolic extracts of Tinospora cordifolia and Alstonia scholaris show antimicrobial activity towards clinical isolates of methicillin-resistant and carbapenemase-producing bacteria. 
Nat Prod Res 28:1438-1445. https://doi.org/10.1080/14786 419.2014.909421

36. Kumar TVR, Murthy JSR, Rao MN, Bhargava Y (2016) Evaluation of silver nanoparticles synthetic potential of Couroupita guianensis Aubl., flower buds extract and their synergistic antibacterial activity. 3 Biotech 6:92-98. https://doi.org/10.1007/s1320 5-016-0407-9

37. Zhou Q, Lv J, Ren Y, Chen J, Gao D, Lu Z, Wang C (2017) A green in situ synthesis of silver nanoparticles on cotton fabrics using aloe vera leaf extraction for durable ultraviolet protection and antibacterial activity. Text Res J 87:2407-2419. https://doi. org/10.1177/0040517516671124

38. Rao AV, Ashok B, Umamahesh M, Chandrasekhar V, Subbareddy GV, Rajulu AV (2018) Preparation and properties of silver nanocomposite fabrics with in situ-generated silver nano particles using red sanders powder extract as reducing agent. Int J Polym Anal Charact 23:493-501. https://doi.org/10.1080/10236 66X.2018.1485200

39. Jayaseelan C, Rahuman AA, Rajakumar G, Kirthi AV, Santhoshkumar T, Marimuthu S, Elango G (2011) Synthesis of pediculocidal and larvicidal silver nanoparticles by leaf extract from heartleaf moonseed plant, Tinospora cordifolia Miers. Parasitol Res 109:185-194. https://doi.org/10.1007/s00436-010-2242-y

40. Kumar V, Singh DK, Mohan S, Hasan SH (2016) Photo-induced biosynthesis of silver nanoparticles using aqueous extract of Erigeron bonariensis and its catalytic activity against Acridine Orange. J Photochem Photobiol B Biol 155:39-50. https://doi. org/10.1016/j.jphotobiol.2015.12.011
41. Aravinthan A, Govarthanan M, Selvam K, Praburaman L, Selvankumar T, Balamurugan R, Kim JH (2015) Sunroot mediated synthesis and characterization of silver nanoparticles and evaluation of its antibacterial and rat splenocyte cytotoxic effects. Int J Nanomed 10:1977-1986. https://doi.org/10.2147/IJN.S79106

42. Mary G, Bajpai SK, Chand N (2009) Copper (II) ions and copper nanoparticles-loaded chemically modified cotton cellulose fibers with fair antibacterial properties. J Appl Polym Sci 113:757766. https://doi.org/10.1002/app.29890

43. Pai $S$, Sridevi $H$, Varadavenkatesan $T$, Vinayagam R, Selvaraj $R$ (2019) Photocatalytic zinc oxide nanoparticles synthesis using Peltophorum pterocarpum leaf extract and their characterization. Optik 185:248-255. https://doi.org/10.1016/j.ijleo.2019.03.101

44. Dash A, Ahmed MT, Selvaraj R (2019) Mesoporous magnetite nanoparticles synthesis using the Peltophorum pterocarpum pod extract, their antibacterial efficacy against pathogens and ability to remove a pollutant dye. J Mol Struct 1178:268-273. https:// doi.org/10.1016/j.molstruc.2018.10.042

45. Prabhu S, Poulose EK (2012) Silver nanoparticles: mechanism of antimicrobial action, synthesis, medical applications, and toxicity effects. Int Nano Lett 2:32. https://doi. org/10.1186/2228-5326-2-32

Publisher's Note Springer Nature remains neutral with regard to jurisdictional claims in published maps and institutional affiliations. 